\title{
A pequena produção e a exploração sustentável de madeira na Amazônia
}

Frank Merry - Pesquisador do Woods Hole Research Center (WHRC).

Oriana Almeida - Prof. do Núcleo de Altos Estudos Amazônicos da UFPA.

Erivelton Lima - Funcionário do Banco Interamericano de Desenvolvimento (BID).

Dan Nepstad - Pesquisador da Moore Foundation.

Gregory Amacher - Pesquisador Virginia Tech.

Cláudia Azevedo-Ramos - Profa do Núcleo de Altos Estudos Amazônicos da UFPA.

Paul Lefebvre - Pesquisador do Woods Hole Research Center (WHRC).

Felipe Resque Júnior - Pesquisador do Instituto de Pesquisa Ambiental da Amazônia (IPAM).

\section{Resumo}

Esta pesquisa estima o potencial e a importância do pequeno produtor para o abastecimento da indústria madeireira na Transamazônica. Através de imagens de satélites, dados secundários e dados primários o trabalho mostra o potencial e sustentabilidade da pequena produção abastecer a indústria. Considerando uma estimativa conservadora de produção madeireira estima-se uma área de 841.954 ha por ano o que equivaleria a exploração de madeira de 10.000 famílias por ano ou $18 \%$ do total estimado de famílias para suprir a demanda atual da indústria nesta área a preço de mercado. Isso equivale a um volume que é 1/25 da atual estimativa para a produção de madeira na região provenientes de outros estudos. Em geral a pesquisa tem focado no manejo florestal de industria madeireira, mas uma análise mais ampla do potencial madeireiro da pequena produção, quando calculado para uma regiao, pode ser usado para trazer o desenvolvimento econômico integrando desenvolvimento agrícola com desenvolvimento florestal.

\section{Palavras-chave}

Sustentabilidade; atividade madeireira; pequeno produtor; Amazonia.

\section{Abstract}

This research estimate the potential and importance of the small holder for wood supply to the logging industry in the Transamazonic. Using satellite images, secondary and primary data the research showed the potential and the sustainability of the small production to supply the industry. Using a conservative estimate per hectare it was possible to estimate a area of 841,954 ha per year to exploit in the region which would be equivalent to the production of 10,000 families or $18 \%$ of the total estimated family in the region. This is equivalent to 1/25 of the actual estimate of production in the region. In general, the large potential of the small production are overlooked but when calculated for a large region it can show the potential for increase of income and forestry sustainability.

\section{Keywords}

Sustainability, sawmills, small producer, Amazonia. 
O atual debate sobre políticas florestais tem-se voltado para a exploração do potencial madeireiro das áreas do Instituto Nacional de Colonização e Reforma Agrária (INCRA), como uma importante fonte de suprimentos de madeira que possibilitará um desenvolvimento econômico mais amplo e justo nas fronteiras florestais. Aqui será abordado o potencial de madeira nas áreas da rodovia Transamazônica, e será descrito um projeto que há muito tempo trabalha para firmar um justo trato comercial da madeira com as famílias proprietárias.

Construída no governo do general Médici (1969-1974), parte da rodovia Transamazônica estende-se por cerca de 800 km, indo da cidade de Marabá até Itaituba, na calha do rio Tapajós ${ }^{1}$. A rodovia não tem, em grande parte, pavimentação e é virtualmente inacessível durante os quatro meses de estação de chuvas. Os pequenos proprietários localizamse normalmente em lotes de 100 ha e entram, com freqüência, em conflito com especuladores ou grandes proprietários de terra no processo de ocupação da terra (ALSTON; LIBECAP; MUELLER, 1999, 2000). Assim, a migração para a região é grande, com um fluxo constante de controle formal e informal de terras, desde os projetos de colonização que datam de 1970. O INCRA, órgão federal de demarcação de terras, assentou formalmente aproximadamente 30.000 famílias, às quais se soma um número desconhecido de colonizadores informais (MERRY et al., 2006).

Sabe-se que pequenos produtores controlam grandes faixas de terra ao longo da rodovia Transamazônica, mas a quantificação dessa área é incerta. A área que ocupa 100 quilômetros de cada lado da rodovia Transamazônica - considerando-se uma faixa que vai do município de Itupiranga até Placas - foi mapeada, utilizando-se para isso imagens de satélite e informações secundárias do INCRA e do Instituto Brasileiro do Meio Ambiente e dos Recursos Naturais Renováveis (IBAMA). A distribuição de terras e o desflorestamento foram mapeados usando-se uma resolução espacial de imagens de satélite de 30 metros e informações secundárias do INCRA e do Instituto Brasileiro de Geografia e Estatística (IBGE). As imagens foram classificadas em florestais e não florestais com base em uma classificação supervisionada e interpretação visual. O objetivo era localizar onde se encontram atualmente os pequenos proprietários e onde se localizarão no futuro.

\footnotetext{
${ }^{1}$ A rodovia Transamazônica percorre aproximadamente $3.300 \mathrm{~km}$, conectando o Estado de Tocantins ao Estado do Acre, perto da fronteira peruana. A área situada a oeste da que é alvo de nossa discussão, que se estende de Itaituba à cidade de Humaitá (seguindo a parte oeste do rio Tapajós), é praticamente inabitada, mas deverá ser a futura fronteira, importante para a história daqui a alguns anos.
} 
De um total de 15,7 milhões de hectares localizados nessa faixa, 7,9 milhões estão sob o controle de pequenos produtores ou são a eles destinados. A distribuição de terra configura-se da seguinte maneira: 1,1\% corresponde a áreas demarcadas; 5,4\% são assentamentos atuais; $11,4 \%$ estão com posseiros ${ }^{2} ; 13,2 \%$ são ocupadas por antigos projetos de colonização; 19,5\% são destinados a futuros assentamentos do INCRA; 4\% da terra são áreas de conservação; 7,6\% pertencem a grandes e médios proprietários; $15,4 \%$ são situadas em reservas indígenas; finalmente, 21,2\% são terras devolutas. Para levantar o número de proprietários que atualmente residem no interior da faixa de $100 \mathrm{~km}$ de cada lado ao longo da estrada, dividiu-se a área total com projetos ativos, que incluem assentamentos atuais, colonização e posseiros, em lotes de 82,6 ha, tamanho médio, com base nos resultados de entrevistas na região. O resultado foi uma área total de aproximadamente 4,7 milhões ha ocupados por 57.000 famílias.

Dada a distribuição dos pequenos produtores observada nas análises, pode-se perguntar qual o papel desses agentes no suprimento da indústria madeireira da região. A demanda por madeira na área é grande; entre 1990 e 2002, a demanda na rodovia Transamazônica mais que duplicou, aumentando de $342.264 \mathrm{~m}^{3}$ em 1990 para $841.954 \mathrm{~m}^{3}$. Para determinar se os pequenos proprietários podem suprir essa demanda, primeiro deve ser estimado o crescimento potencial do estoque da área sob o controle dos proprietários, considerando que eles irão, de fato, vender madeira (voltaremos a essa hipótese mais adiante). Partindo de uma estimativa de desmatamento alta e conservadora (ou seja, de uma taxa de 60\% de desflorestamento para as áreas antigas de colonização, e de até 15\% de desflorestamento para terras do INCRA locadas em assentamentos futuros) ${ }^{3}$ e de um valor conservador de 10 $\mathrm{m}^{3}$ de madeira por ha, estima-se que o atual estoque das florestas em áreas ativas de assentamentos é de 25,8 milhões $\mathrm{m}^{3}$. Considerando um ciclo de extração de 30 anos, isso daria um volume de colheita sustentável de $860.547 \mathrm{~m}^{3}$ ao ano, um valor próximo à demanda atual, que, a um preço estimado ${ }^{4}$ de $\mathrm{R} \$ 10,00$ por $\mathrm{m}^{3}$, geraria $\mathrm{R} \$$ 8,6 milhões por ano

\footnotetext{
${ }^{2}$ A área total para posseiros era de 19\%, 60\% dos quais devem ser pequenos proprietários, os restantes $40 \%$ são médios e grandes proprietários.

${ }^{3}$ Esses resultados também mostraram que apenas 1\% da área demarcada está atualmente desmatada. Então, essas estimativas podem ser consideradas bem conservadoras para o desmatamento.

${ }^{4}$ Foi usado o preço de R\$ 10,00 com base em uma estimativa conservadora do exemplo de um contrato formal entre pequenos proprietários e a indústria próxima a Santarém. Nesse caso, uma madeireira está pagando em média R\$12,00 para qualquer tipo de espécie
} 
(LENTINI; VERÍSSIMO; SOBRAL, 2003; LENTINI et al., 2005; SMERALDI et al., 1999; SOBRAL et al., 2002). Para colocar isso em perspectiva, se as áreas dos pequenos proprietários no interior dos atuais assentamentos fossem usadas até o máximo potencial, e os benefícios, distribuídos eqüitativamente entre as famílias (que são estimadas em 57.000), cada proprietário poderia receber $\mathrm{R} \$ 150,00$ por ano.

Assumindo que as famílias proprietárias de terra eventualmente se assentarão em áreas demarcadas pelo INCRA, teremos uma estimativa de estoque de 52,6 milhões de $\mathrm{m}^{3}$, o que poderia render uma extração sustentável de aproximadamente 1,7 milhões de $\mathrm{m}^{3}$ por ano, ou mais do que o dobro da demanda regional atual. Assim, o atual potencial do estoque florestal parece ser suficiente para atender a demanda e uma excelente oportunidade para uma redistribuição de riqueza, e os pequenos produtores deveriam ter um mercado sem entraves para a venda da madeira (MERRY; AMACHER, no prelo) (Tabela 1).

Tabela 1: Potencial de madeira das áreas dos pequenos proprietários na rodovia Transamazônica.

\begin{tabular}{|c|c|c|c|c|c|c|}
\hline Pequenos produtores & $\begin{array}{l}\text { Área Total } \\
\text { (ha) }\end{array}$ & $\%$ & $\begin{array}{l}\text { Cobertura } \\
\text { vegetal } \%\end{array}$ & $\begin{array}{l}\text { Área de } \\
\text { Floresta }\end{array}$ & $\begin{array}{l}\text { Estoque de } \\
\text { Madeira } \\
\left(\mathrm{m}^{3}\right)\end{array}$ & $\begin{array}{c}\text { Fluxo } \\
\text { Potencial de } \\
\text { Madeira } \\
\left(\mathrm{m}^{3} / \text { year }\right)\end{array}$ \\
\hline Colonização futura & 3.055 .000 & 19,5 & 85 & 2.596 .000 & 25.965 .000 & 865.000 \\
\hline Projetos de Colonização & 2.063 .000 & 13,2 & 40 & 825.000 & 8.252 .000 & 275.000 \\
\hline Colonização Informal & 1.792 .000 & 11,4 & 60 & 1.075 .000 & 10.750 .000 & 358.000 \\
\hline Colonização do INCRA & 852.000 & 5,4 & 80 & 682.000 & 6.815 .000 & 227.000 \\
\hline Colonização demarcada & 169.000 & 1,1 & 50 & 85.000 & 847.000 & 28.000 \\
\hline Total & 7.931 .000 & 50,6 & - & 5.263 .000 & 52.629 .000 & 1.753 .000 \\
\hline
\end{tabular}

No entanto, é necessário perguntar se essas estimativas baseadas em informações governamentais são compatíveis com os dados do campo. Para responder a essa pergunta, serão utilizados dados de uma pesquisa socioeconômica sobre pequenos produtores instalados ao longo da rodovia Transamazônica, realizada pelo Instituto de Pesquisas

(LIMA et al., 2003). Também em uma concessão de floresta (3 anos em contrato) na Floresta Nacional do Tapajós e no projeto International Tropical Timber Organization (ITTO), feito pelo IBAMA, o valor do estoque de madeira- equivalente ao que eles consideram ser o valor da madeira - para três categorias de preço, carregado pelo IBAMA em 2003 era R\$ 11,73. O cenário apresentado neste artigo não assume mudanças nos preços ao longo do tempo. Como qualquer economista admitirá, essa observação é relevante. Quanto mais madeira entrar nos mercados, mais os preços cairão, o que afetaria a renda e o volume disponível do sistema dos pequenos proprietários. Mas esse comentário é verdadeiro para o mercado de madeira como um todo no Brasil. Para referências sobre os mercados de madeira, ver www.imazon.org.br (LENTINI; VERÍSSIMO; SOBRAL, 2003; LENTINI et al., 2005; SMERALDI; VERÍSSIMO, 1999). 
Ambientais da Amazônia (IPAM), pelo Woods Hole Research Center e pela Fundação Viver, Produzir e Preservar (FVPP). Entre junho e dezembro de 2003, foram entrevistadas por essas instituições aproximadamente 3.000 famílias, das quais 2.441 viviam dentro do perímetro demarcado de 100 quilômetros ${ }^{5}$.

Nessas entrevistas, foram coletados dados sobre a produção madeireira do pequeno produtor e informações socioeconômicas. Os resultados mostraram que $26 \%$ das famílias tinham vendido madeira e que tais vendas ocorreram nos últimos cinco anos. Somente uma venda por lote foi feita. 96\% dos pequenos proprietários venderam a madeira como árvores em pé - e a média de árvores vendidas foi de 20 árvores por proprietário, o que corresponde a uma taxa de extração de aproximadamente uma árvore a cada cinco hectares e, tomando um volume médio de $5 \mathrm{~m}^{3}$ de madeira por árvore, um volume de vendas médio de $100 \mathrm{~m}^{3}$. O valor de venda média era de $\mathrm{R} \$$ 173,00 por família, o que corresponde a $\mathrm{R} \$$ 8,65 por árvore ou $\mathrm{R} \$ 1,73$ por $\mathrm{m}^{36}$.

Comparando-se essas observações com os resultados da análise geoespacial apresentados acima, baseados na produção de madeira oriunda do desmatamento legal e na extração de madeira das "reservas legais" (a área de pequenos proprietários de terra que deve ser mantida como floresta), os produtores estão vendendo aproximadamente $1 \mathrm{~m}^{3}$ por hectare, e não $10 \mathrm{~m}^{3}$, e somente $26 \%$ do total de produtores venderam necessariamente madeira. Com esse volume de extração, seria necessária uma área de 841.954 ha por ano (ou a exploração de madeira de 10.000 famílias por ano, que correspondem a aproximadamente 18\% do total estimado de famílias) para suprir a demanda atual da indústria nessa área, a preço de mercado. Isso equivale a um volume que equivale a 1/25 da atual estimativa, feita em outros estudos, para a produção de madeira na Amazônia (BARRETO et al., 1998; HOLMES et al., 1999). Se a intensidade de extração fosse de $10 \mathrm{~m}^{3} /$ há, seriam necessárias apenas 1.000 famílias por ano ou 1,8\% de todas as famílias para suprir a necessidade de madeira da indústria. Esse nível de participação (1,8\% das famílias) poderia ser facilmente alcançado.

\footnotetext{
${ }^{5}$ Os resultados preliminares da pesquisa foram apresentados aos proprietários em seminários realizados em junho de 2004 .

${ }^{6}$ O preço estimado no portão da fábrica em 2002 na rodovia Transamazônica foi de R \$ 58,00 por $\mathrm{m}^{3}$, e foi calculado um desajuste de 5 anos nos preços de madeira de 1998 a 2002 no valor de R\$ 39 por $\mathrm{m}^{3}$, mas isso antes de incluir o custo da extração para fronteiras intermediárias - para alcançar a rodovia Transamazônica, é preciso contar entre R\$ 30,00 e R\$ 40,00 por $\mathrm{m}^{3}$ - e o custo de transporte - a distância entre as áreas de exploração e as fábricas pode atingir 80 ou 90 quilômetros.
} 
O paradigma para comunidades florestais é o seguinte: indivíduos pertencentes às comunidades trabalham coletivamente, controlam totalmente a linha de produção por meio da venda de produtos finais e consideram um problema a interação formal com a indústria madeireira. Essa visão, na realidade, tem restringido o potencial de comunidades florestais na Amazônia, já que vários modelos são possíveis. Atualmente, existem mais de 500.000 pequenos produtores na Amazônia brasileira que trabalham individualmente, ou em associações comunitárias, e que se especializaram, mesmo que de forma ainda não eficiente, no fornecimento de árvores em pé, trabalhando em estrita colaboração com empresas madeireiras.

Entretanto, a maioria das operações das comunidades florestais de pequenos produtores que estão sendo realizadas na Amazônia atualmente tem dois problemas centrais. Primeiro, ao lidar com pequenos proprietários em uma base individual, os madeireiros possuem todas as vantagens. Eles têm mais informações sobre as espécies e o valor da madeira e exploram as necessidades financeiras imediatas dos pequenos proprietários mais pobres. Em segundo lugar, madeira em lotes de produtores é legal somente sob duas premissas: primeiro, o produtor deve possuir uma licença para desmatar, tendo como limite por lei uma

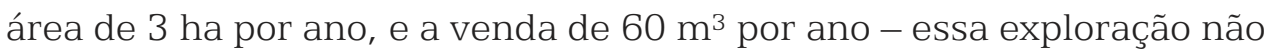
poderá exceder $20 \%$ da propriedade; segundo, o produtor tem a opção de desenvolver um plano de manejo florestal, que deve ser aprovado pelo IBAMA. Das vendas registradas nas pesquisas, 26\% foram de desflorestamentos autorizados, e um volume relevante de 79\% vem de "reservas legais" de cada propriedade. Como nenhum plano formal de manejo florestal tem sido desenvolvido por esses sistemas de exploração por produtores, quase $80 \%$ das vendas de madeira dos proprietários normalmente são ilegais, segundo as normas do governo. Some-se a isso o fato de que poucos produtores conseguem uma autorização legal para desflorestamento.

Uma questão impõe-se: por que não há planos de manejo formais? É preciso lembrar que um projeto de manejo florestal requer que o produtor possua um título legal. Ainda que 95\% dos produtores pesquisados tenham afirmado que são os donos das propriedades, foi detectado que somente $11 \%$ possuem o título legal de posse, um valor confirmado por pesquisas anteriores na região (ALSTON; LIBECAP; MUELLER, 1999, 2000). Essa falta de coordenação entre agências ambientais e fundiárias é a maior barreira para vencer a venda ilegal de madeira dentro do sistema da pequena propriedade e para integrar os pequenos proprietários dentro do mercado formal de madeira. 
Mas a coordenação entre órgãos de governo não é uma tarefa impossível. Por exemplo, em um caso recente, uma parceria entre os madeireiros e os pequenos produtores, com uma ajuda intermitente das agências de governo, encontrou uma solução criativa para o problema na forma de uma parceria entre indústria e produtores. Nesse caso, as associações comunitárias subcontratavam as madeireiras para planejar e implementar a extração, enquanto o governo tinha a responsabilidade de expedir títulos e aprovar o manejo. A posse da terra (ou a concessão de uso, dependendo do caso) é individual, e os planos de manejo são feitos para cada lote privado de 100 ha, mas as negociações são feitas entre a madeireira e as associações comunitárias. A comunidade pode demandar maiores preços vendendo como um grupo, e as madeireiras têm seus estoques assegurados por um longo tempo. Como resultado, as operações legais em florestas estão começando a ocupar um maior espaço, e os pequenos produtores estão recebendo uma parcela mais justa dos benefícios da extração de madeira em sua própria terra (LIMA et al., 2003; NEPSTAD et al., 2004a; NEPSTAD et al., 2004b).

\section{QUAL O FUTURO?}

O que esses resultados podem dizer sobre a questão das madeireiras e das políticas florestais? Lembremos que o principal impulso das novas políticas florestais baseia-se na concessão de madeira em terras públicas. Trata-se de um programa efetivo para uma parcela da indústria, mas exige alguns cuidados. Em alguns corredores econômicos, onde existem muitos pequenos proprietários, como no caso da região ao redor da rodovia Transamazônica, grande parte da área passível de exploração madeireira (ou seja, excluindo-se as unidades de conservação e as áreas indígenas) está sob o controle de pequenos produtores ou está destinada a eles. Nessas regiões, portanto, há grande potencial de inclusão social no setor florestal. Atualmente, existem mais de 500.000 famílias assentadas na Amazônia. Desse total, uma parte considerável possui largas extensões de cobertura vegetal em suas áreas e poderia estar utilizando os recursos florestais como complemento da renda familiar e ainda contribuindo para o suprimento potencial de madeira da região. Em alguns assentamentos, a pesquisa tem mostrado que o valor de uma simples extração pode equivaler a mais de 15 anos de produção agrícola (MERRY; AMACHER, no prelo). A fim de promover áreas florestais sustentáveis, é necessária uma regularização tanto fundiária quanto produtiva (licenças ambientais, planos de manejo). Para tanto, uma coordenação entre as agências governamentais é 
fundamental para que áreas prioritárias possam receber ações sincronizadas e servir de vitrine para outras regiões. Reduzir os custos das transações e apoiar a produção sustentável é condição fundamental para incentivar a produção legal.

Projetos de manejo florestal em lotes de assentamentos de pequenos proprietários na Amazônia brasileira, se amplamente adotados, ajudarão a levar a região ao desenvolvimento econômico com base florestal e a uma solução pacífica para os problemas que atualmente as famílias migrantes enfrentam. Essa não é a única solução para essa questão na Amazônia, mas é um passo à frente e está ao alcance da atual administração. Sem mudança, contudo, podem-se esperar futuras degradações da floresta por meio da exploração ilegal e conflitos constantes, o que dificultará o desenvolvimento econômico e a justiça social nas fronteiras da Amazônia. 


\section{REFERÊNCIAS}

ALSTON, L. J.; LIBECAP, G. D.; MUELLER, B. Titles, Conflict, and Land Use: The Development of Property Rights and Land Reform on the Brazilian Amazon Frontier. Ann Arbour, Michigan, USA: The University of Michigan Press, p. 227, 1999.

ALSTON, L. J.; LIBECAP, G. D.; MUELLER, B. Land Reform Policies, the Sources of Violent Conflict, and Implications for Deforestation in the Brazilian Amazon. Journal of Environmental Economics and Management, v. 39, n. 2, p. 162-188, 2000.

BARRETO, P.; AMARAL, P.; VIDAL, E.; UHL, C. Costs and Benefits of Forest Management for Timber Production in Eastern Amazonia. Forest Ecology and Management, v. 108, n. 1-2, p. 9-26, 1998.

HOLMES, T. P.; BLATE, G. M.; ZWEEDE, J. C.; PEREIRA JÚNIOR, R.; BARRETO, P.; BOLTZ, F.; BAUCH, R.. Financial Costs and Benefits of Reduced Impact Logging Relative to Conventional Logging in the Eastern Amazon. Washington, D.C.: Forest Foundation, 1999. 77 p.

LENTINI, M.; PEREIRA, D.; CELENTANO, D.; PEREIRA, R. Fatos florestais. Belém: Imazon, p. 141, 2005.

LENTINI, M.; VERÍSSIMO, A.; SOBRAL, L. Fatos florestais. Belém: Imazon, p. 110, 2003.

LIMA, E.; LEITE, A. A.; NEPSTAD, D.; KALIF, K.; AZEVEDO-RAMOS, C.; PEREIRA, C.; ALENCAR, A.; LOPES, U.; MERRY, F. Florestas familiares: um pacto socioambiental entre a indústria madeireira e a agricultura familiar na Amazônia. Belém: IPAM, p. 106, 2003.

MERRY, F. D.; AMACHER, G. S. Emerging Smallholder Forest Management Contracts in the Brazilian Amazon: Labor Supply and Productivity Effects. Environment and Development Economics. No prelo.

MERRY, F. D.; AMACHER, G. S.; LIMA, E.; GUIMARAES DOS SANTOS, M.; MACQUEEN, D.; NEPSTAD, D. Collective Action without Collective Ownership: The Role of Formal Logging Contracts in Community Associations on the Brazilian Amazon Frontier. International Forestry Review, v. 8, p. 211-221, 2006. 
Frank Merry / Oriana Almeida / Erivelton Lima / Dan Nepstad / Gregory Amacher / Cláudia Azevedo-Ramos / Paul Lefebure / Felipe Resque Jr.

NEPSTAD, D.; AZEVEDO-RAMOS, C.; LIMA, E.; MCGRATH, D.; PEREIRA, C.; MERRY, F. Managing the Amazon Timber Industry. Conservation Biology, v. 18, n. 2, p. 1-3, 2004a.

NEPSTAD, D.; ALENCAR, A.; BARROS, A. C.; LIMA, E.; AZEVEDORAMOS, C.; RIVERO, S.; LEFEBVRE, P. Governing the Amazon Timber Industry. In: ZARIN, D.; ALAVALAPATI, J. R. R.; PUTZ, F. E.; SCHMINK, M. (Ed.). Working Forests in the American Tropics: Conservation through Sustainable Management? New York: Columbia University Press, p. 388414, 2004b.

SMERALDI, R.; VERÍSSIMO, A. Acertando o alvo. São Paulo: Amigos da Terra; Imaflora; Imazon, p. 41, 1999.

SOBRAL, L.; VERÍSSIMO, A.; LIMA, E.; AZEVEDO, T.; SMERALDI, R. Acertando o alvo 2. Belém: Imazon, p. 71, 2002. 